\title{
Effect of Aggregate Gradation with Fuller Distribution on Properties of Sulfoaluminate Cement Concrete
}

\author{
Chenchen Gong, Jie Zhang, Shoude Wang, Wen Zong, and Lingchao Lu \\ School of Materials Science and Engineering, University of Jinan \\ Shandong Provincial Key Laboratory of Preparation and Measurement of Building Materials
}

\begin{abstract}
Aggregate, the main ingredient of concrete, has a great effect on mechanical property and durability of concrete. Sulfoaluminate cement has lots of special properties such as high early-age compressive strength, fast hydration and setting rate, and hydration with slight swelling. But effect of aggregate gradation with Fuller distribution on properties of sulfoaluminate cement concrete was seldom studied. Hence, in this paper, experimental investigations on mechanical property and durability of sulfoaluminate cement concrete with aggregate gradations according to Fuller distribution were presented. Fuller distribution of aggregates was beneficial to the close packing of aggregates, and the packing density was changed by adjusting the aggregate gradations. Compressive strength, water impermeability, and resistance capability to sulfate attack of SACC have the same trend of concrete with fine aggregates of Fuller distribution gradation < concrete with fine aggregates of Fuller distribution gradation < concrete with fine aggregates of Fuller distribution gradation. The relationship between packing density of aggregate and water penetration depth obeyed the second-order polynomial $y=0.002 x^{2}-6.8638 x+5862.3$ and had a notable correlation $R^{2}=0.9799$. The sulfoaluminate cement concrete with total aggregate gradation with Fuller distribution for $h=0.50$ had the best resistance capability to sulfate attack. It was a second-order polynomial relationship between packing density of aggregates and water penetration depth of $y=0.002 x^{2}-6.8638 x+5862.3$ with $R^{2}=0.9799$, which indicated notable correlation. The fitting formula between packing density of aggregates and sulfate resistance coefficient of SACC was $y=0.0 .0005 x+0.3704$ with $R^{2}=0.9585$.
\end{abstract}

\section{INTRODUCTION}

Sulfoaluminate cement (SAC) has lots of special properties such as high early-age compressive strength, fast hydration and setting rate, hydration with slight swelling, and so on, which has great advantages to be used in the marine engineering and waterproof/ leakage engineering (Huaxin, Jiaping, Jianzhong, \& Changfeng, 2012; Xin, Jun, Lingchao, Futian, \& Bing, 2000, 2004). Sulfoaluminate cement concrete (SACC) as a kind of special cement concrete has not been studied deeply about the ingredients, mechanical property, durability property, and their relationships, although there is broad prospects.

It is known that aggregates take up $60-80 \%$ of total volume of concrete, which is the most commonly used building material worldwide. Concrete properties such as mechanical and durability properties are highly affected by aggregate properties such as aggregate gradation (Ashraf \& Noor, 2011; Ergul, Yasin, \& Alaettin, 2004; loannis \& Konstantinos, 2013; Mucteba, Kemalettin, \& Metin, 2010; Rafat, Paratibha, \& Yogesh, 2012; Ronnen \& Hashem, 2002; Sari \& Pasamehmetoglu, 2005; Abdel-Jawad \& Abdullah, 2002). Good aggregate gradation corresponds to high packing density and properties of concrete.
The most well-known methods of aggregate gradation include (1) using two different segments of aggregates (i.e., fine aggregates and coarse aggregates) and (2) using total aggregate gradation that is combined with aggregate gradation. Among these methods, Fuller distribution, the maximum density theory established by Fuller and Thompson, is the classical aggregate gradation theory (Bolomey, 1927; Fuller \& Thompson, 1907).

Most of the researches between aggregates and concrete properties focus on Portland cement concrete. But hydrating process and machine of sulfoaluminate cement are different to Portland cement. In this paper, the effect of aggregate gradation with Fuller distribution on properties of sulfoaluminate cement concrete was studied. Each aggregate was viewed as a sphere particle. The volume percentages of aggregates in size groups were calculated according to the Fuller distribution to obtain different aggregate gradations. The packing densities of aggregates with prepared gradations were tested. Then the mechanical property and durability of sulfoaluminate cement concrete with various aggregate gradations were investigated. The relationship between packing densities-compressive strength, packing densities-water penetration depth, and packing densities-sulfate resistance coefficient were analyzed at the same time. 


\section{MATERIALS AND METHODS}

2.1 Materials

2.1.1 Cement

Sulfoaluminate cement used in this paper was made by special cement plant of Zaozhuang in china. The chemical compositions and physical properties of cement were presented in Tables 1 and 2 .

\subsubsection{Superplasticizer (SP)}

In this paper, a polycarboxylate polymer with long comb-type side chain was used as SP and its waterreducing ratio in SAC was over $20 \%$.

\subsubsection{Aggregates}

The river sands (0.075-2.36 $\mathrm{mm}$ in size) were used as fine aggregates that had dry surface saturated specific gravity of $2710 \mathrm{~kg} / \mathrm{m}^{3}$ and water absorption of $0.24 \%$. The natural crushed stones $(2.36-16 \mathrm{~mm}$ in size) were applied as coarse aggregates that had dry surface-saturated specific gravity of $2740 \mathrm{~kg} / \mathrm{m}^{3}$ and water absorption of $0.40 \%$.

\subsection{Mixture proportions}

\subsubsection{Mixture proportions of aggregates with Fuller} distribution

Fuller distribution is a typical wide particle size distribution that is applied to concrete aggregate gradations to achieve maximum packing density. The equation is showed as Equation (1).

$$
U(i)=100 \times\left(i / D_{\max }\right)^{h},
$$

where $i$ is the diameter of aggregate in each size group $(\mathrm{mm}) ; U(i)$ is the cumulative volume of aggregate under i $\mathrm{mm}(\%) ; D_{\max }$ is the maximum diameter of aggregate in all size groups ( $\mathrm{mm}$ ); and $h$ is the Fuller exponential.

Studies showed that aggregate particles were closely stacked when $h$ was in the range of $0.33-0.50$ [14]. Hence, Fuller distribution with $h=0.33$ and 0.50 was selected to determine volume percentage of aggregates in each size group.

To define the optimal mixture proportions to obtain satisfactory mechanical properties, fine aggregates were classified into five groups of $0.075-0.15,0.15$ $0.3,0.3-0.6,0.6-1.18$, and 1.18-2.36 mm; coarse aggregates were classified into three groups of 2.36 4.75, 4.75-9.6, and 9.6-16 mm.

The proportions of aggregates in each size group could be calculated according to Equation (2).

$$
d_{U(i+1)}=U(i+1)-U(i)
$$

$$
\begin{array}{ll}
0.075-0.15 \mathrm{~mm}, & d_{U(0.15-0.075 \mathrm{~mm})}=U(0.15)-U(0.075) \\
0.15-0.3 \mathrm{~mm}, & d_{U(0.3-0.15 \mathrm{~mm})}=U(0.3)-U(0.15) \\
\ldots . . & \ldots . . \\
9.5-16 \mathrm{~mm} & d_{U(16-9.5 \mathrm{~mm})}=U(16)-U(9.5)
\end{array}
$$

So if $h=0.33$,

$$
\begin{aligned}
& d_{U(0.075-0.15 \mathrm{~mm})}: d_{U(0.15-0.3 \mathrm{~mm})}: \ldots \ldots . d_{U(9.6-16 \mathrm{~mm})}= \\
& \quad\left(0.15^{0.33}-0.075^{0.33}\right):\left(0.3^{0.33}-0.15^{0.33}\right): \ldots \ldots . \\
& \left(16^{0.33}-9.6^{0.33}\right)
\end{aligned}
$$

As was known that

$$
d_{U(i+1)}=\frac{d_{w(i+1)}}{\gamma_{i+1}}
$$

where $\gamma_{i}$ was the packing density of aggregate in each size group.

The mass ratio of aggregates in size groups could be calculated according to Equation (4).

$$
\begin{aligned}
d_{w(0.075 \mathrm{~mm}-0.15 \mathrm{~mm})}: d_{w(0.15 \mathrm{~mm}-0.3 \mathrm{~mm})}: \ldots . . . & : d_{w(9.6 \mathrm{~mm}-16 \mathrm{~mm})} \\
= & \left(0.15^{0.33}-0.075^{0.33}\right) \cdot \gamma_{(0.075 \mathrm{~mm}-0.15 \mathrm{~mm})}: \\
& \left(0.3^{0.33}-0.15^{0.33}\right) \cdot \gamma_{(0.15 \mathrm{~mm}-0.30 \mathrm{~mm})} \cdots \\
& \ldots\left(16^{0.33}-9.6^{0.33}\right) \cdot \gamma_{(9.6 \mathrm{~mm}-16 \mathrm{~mm})}
\end{aligned}
$$

\begin{tabular}{|c|c|c|c|c|c|c|c|c|}
\hline \multirow{3}{*}{$\begin{array}{l}\text { Specific surface } \\
\text { area }\left(\mathrm{m}^{2} / \mathrm{kg}\right)\end{array}$} & \multicolumn{2}{|c|}{ Setting time (min) } & \multicolumn{6}{|c|}{ Mechanical properties (MPa) } \\
\hline & \multirow{2}{*}{ Initial setting } & \multirow{2}{*}{ Final setting } & \multirow{2}{*}{$\begin{array}{c}\text { Flexural strength } \\
1 \text { day }\end{array}$} & \multicolumn{5}{|c|}{ Compressive strength } \\
\hline & & & & 3 days & 28 days & 1 day & 3 days & 28 days \\
\hline 358 & 18 & 37 & 4.5 & 6.2 & 6.4 & 26.0 & 37.1 & 44.1 \\
\hline
\end{tabular}

The volume percentages of aggregates with different gradations were shown in Table 3. G0 was the control specimen with common aggregates. G1 and G2 were concretes with fine aggregate gradation met with Fuller distribution for $h=0.33$ and 0.50 , respectively. G3 and G4 were concretes with coarse aggregate

Table 1. Chemical compositions of sulfoaluminate cement/\%.

\begin{tabular}{ccccccccccc}
\hline $\mathrm{LOI}$ & $\mathrm{SiO}_{2}$ & $\mathrm{Al}_{2} \mathrm{O}_{3}$ & $\mathrm{Fe}_{2} \mathrm{O}_{3}$ & $\mathrm{CaO}$ & $\mathrm{MgO}$ & $\mathrm{SO}_{3}$ & $\mathrm{~K}_{2} \mathrm{O}$ & $\mathrm{Na}_{2} \mathbf{O}$ & $\mathrm{TiO}_{2}$ & $\mathbf{P}_{2} \mathrm{O}_{5}$ \\
\hline 1.15 & 11.41 & 27.87 & 2.59 & 43.86 & 1.2 & 9.59 & 0.45 & 0.15 & 1.27 & 0.11 \\
\hline
\end{tabular}

Table 2. Physical and mechanical properties of sulfoaluminate cement. 
Table 3. Volume percentages of aggregates with different gradations.

\begin{tabular}{|c|c|c|c|c|c|c|c|c|}
\hline Size group $(\mathrm{mm})$ & $0.075-0.15$ & $0.15-0.30$ & $0.30-0.60$ & $0.6-1.18$ & $1.18-2.36$ & $2.36-4.75$ & $4.75-9.50$ & $9.5-16$ \\
\hline G0 & \multicolumn{8}{|c|}{ Common aggregate } \\
\hline G1 & 0.11 & 0.14 & 0.17 & 0.21 & 0.27 & \multicolumn{3}{|c|}{ Common coarse aggregate } \\
\hline G2 & 0.11 & 0.16 & 0.23 & 0.31 & 0.45 & \multicolumn{3}{|c|}{ Common coarse aggregate } \\
\hline G3 & \multicolumn{5}{|c|}{ Common fine aggregate } & 0.34 & 0.43 & 0.39 \\
\hline G4 & \multicolumn{5}{|c|}{ Common fine aggregate } & 0.64 & 0.90 & 0.92 \\
\hline G5 & 0.11 & 0.14 & 0.17 & 0.21 & 0.27 & 0.34 & 0.43 & 0.39 \\
\hline G6 & 0.11 & 0.16 & 0.23 & 0.31 & 0.45 & 0.64 & 0.90 & 0.92 \\
\hline
\end{tabular}

Table 4. Packing densities of aggregates in size groups.

\begin{tabular}{lcccccccc}
\hline Size group $(\mathrm{mm})$ & $0.075-0.15$ & $0.15-0.30$ & $0.30-0.60$ & $0.6-1.18$ & $1.18-2.36$ & $2.36-4.75$ & $4.75-9.50$ & $9.5-16$ \\
\hline Packing density $\left(\mathbf{k g} / \mathrm{m}^{3}\right)$ & 1160 & 1210 & 1260 & 1300 & 1300 & 1380 & 1410 & 1440 \\
\hline
\end{tabular}

gradation met with Fuller distribution with $h=0.33$ and 0.50 , respectively. G5 and G6 were concretes with total aggregate gradation met with Fuller distribution for $h=0.33$ and 0.50 , respectively.

The packing densities of aggregates in different size groups were shown in Table 4 . The cumulative contents of aggregates in different size groups were given in Table 5.

Table 5. Cumulative contents of aggregates with different gradations.

\begin{tabular}{lrrrrrrr}
\hline $\begin{array}{l}\text { Aggregate } \\
\text { size (mm) }\end{array}$ & \multicolumn{7}{c}{ Cumulative contents (wt\%) } \\
\cline { 2 - 8 } & G0 & \multicolumn{1}{c}{ G1 } & \multicolumn{1}{c}{ G2 } & \multicolumn{1}{c}{ G3 } & \multicolumn{1}{c}{ G4 } & \multicolumn{1}{c}{ G5 } & \multicolumn{1}{c}{ G6 } \\
\hline $0.075-0.15$ & 4.0 & 4.7 & 3.4 & 3.9 & 3.9 & 5.4 & 2.6 \\
$0.15-0.30$ & 6.5 & 11.0 & 8.3 & 6.2 & 6.2 & 12.4 & 6.3 \\
$0.30-0.60$ & 10.6 & 18.4 & 15.6 & 10.2 & 10.2 & 21.1 & 12.0 \\
$0.6-1.18$ & 16.5 & 28.0 & 25.6 & 16.2 & 16.2 & 32.2 & 19.9 \\
$1.18-2.36$ & 23.9 & 40.4 & 40.4 & 23.5 & 23.5 & 46.7 & 31.6 \\
$2.36-4.75$ & 41.0 & 45.9 & 45.8 & 57.0 & 50.4 & 66.1 & 48.9 \\
$4.75-9.50$ & 62.0 & 62.0 & 62.0 & 81.9 & 77.2 & 83.9 & 74.0 \\
$9.5-16$ & 100 & 100 & 100 & 100 & 100 & 100 & 100 \\
\hline
\end{tabular}

\subsubsection{Mixture proportions of concrete}

Mixture proportions of raw materials used to prepare concrete were calculated in accordance with JGJ 552011 and were showed in Table 6.

SAC content was kept at $428.6 \mathrm{~kg} / \mathrm{m}^{3}$ in all mixtures. The water-to-cement ratio $(\mathrm{W} / \mathrm{C})$ by weight was 0.47 to achieve good liquidity. The amount of total aggregates was maintained at $1731 \mathrm{~kg} / \mathrm{m}^{3}$.

Table 6. Mix proportions of concrete.

\begin{tabular}{lcccc}
\hline Materials & Cement & SP & $\begin{array}{c}\text { Coarse } \\
\text { aggregate }\end{array}$ & $\begin{array}{c}\text { Fine } \\
\text { aggregate }\end{array}$ \\
\hline Mix mass $\left(\mathrm{kg} / \mathrm{m}^{3}\right)$ & 428.6 & 4.28 & 1039 & 692 \\
\hline
\end{tabular}

\subsection{Samples preparations and curing conditions}

The ingredients of concrete were batched by weight. The concrete preparation consists of three mixing processes. First, the cement was premixed with threequarters water for $30 \mathrm{~s}$. Second, fine aggregates and coarse aggregates were added and mixed for $1 \mathrm{~min}$. Third, the remaining water mixed with SP was added and mixed for $1 \mathrm{~min}$. Concrete mixtures were cast into $100 \mathrm{~mm} \times 100 \mathrm{~mm} \times 100 \mathrm{~mm}$ steel molds for compressive strength and the resistance to sulfate attack test, and $175 \mathrm{~mm} \times 185 \mathrm{~mm} \times 150 \mathrm{~mm}$ steel molds for water impermeability test.

Concrete samples were cured at $20 \pm 2^{\circ} \mathrm{C}$ in molds, then removed from the molds after $24 \mathrm{~h}$, and cured at $20 \pm 2^{\circ} \mathrm{C}$ with the relative humidity of $95 \pm 5 \%$ until testing ages.

\subsection{Test methods}

\subsubsection{Packing densities of aggregates}

The packing densities of aggregates in size groups were determined using ASTM C 29/C 29M-97 test method. First, aggregates were dried at $105 \pm 5^{\circ} \mathrm{C}$ to constant mass; then coarse aggregates (size of 2.36-16 mm) were mixed with fine aggregates (size of 0.075$2.36 \mathrm{~mm}$ ) for $3 \mathrm{~min}$ and filled into 10-L container by one time. Finally, surplus aggregates were removed from the top of container. Then the packing density of aggregates could be calculated according to Equation (5).

$$
\rho_{\mathrm{L}}=\frac{m_{2}-m_{1}}{V},
$$

where $\rho_{\mathrm{L}}$ is the packing density of aggregate, $\mathrm{kg} / \mathrm{m}^{3}$; $m_{1}$ is the mass of container, $\mathrm{kg} ; m_{2}$ is the mass of aggregate plus the container, $\mathrm{kg}$; and $V$ is the volume of container, $\mathrm{m}^{3}$.

\subsubsection{Other test methods}

The compressive strength test was carried out at the ages of 1,3 , and 28 days according to GB/T 500812011. Concrete samples cured for 27 days were sealed by liquid paraffin, and water impermeability was determined according to GB/T 50082-2009. The resistance of concrete to sulfate attack was conducted 
in accordance with GB/T 50082-2009, but the initial curing age was 26 days.

\section{RESULTS AND DISCUSSION}

\subsection{The effect of aggregate gradation on the packing density of aggregates}

The packing densities of aggregates with various aggregate gradations were presented in Figure 1. Packing density with aggregates of various gradations ranged from 1500 to $1720 \mathrm{~kg} / \mathrm{m}^{3}$, so aggregate gradation had evident effect on the packing density of aggregates. As was known that when fine aggregates and coarse aggregates existed at the same time, in concrete structure coarse aggregates built the skeleton and fine aggregates filled into the voids between coarse aggregates (this was called filling effect).

G0 without aggregate gradation of Fuller distribution had the lowest packing density, which meant that Fuller distribution was beneficial to the close packing of aggregates. Meanwhile, the packing density of $\mathrm{G} 1$ with fine aggregates of Fuller distribution gradation for $h=0.33$ was increased with only $3 \%$ to $1540 \mathrm{~kg} /$ $\mathrm{m}^{3}$ increasing up. G5 with total aggregates of Fuller distribution gradation for $h=0.33$ was further increased with $15 \%$ to $1720 \mathrm{~kg} / \mathrm{m}^{3}$. Hence, packing densities of aggregates with various gradations showed a significant change trend of $\mathrm{G} 1(\mathrm{G} 2)<\mathrm{G} 3(\mathrm{G} 4)<$ $\mathrm{G}$ (G6). The reason was shown in Figure 2. For G1 and $\mathrm{G} 2$, coarse aggregates with free gradation greatly determined concrete structure, while fine aggregates with designed Fuller distribution only made the local density and had little effect to packing density of all aggregates. And coarse aggregates of G3 and G4 presented well-organized Fuller distribution, which resulted in higher packing densities than $\mathrm{G} 1$ and $\mathrm{G} 2$. But because fine aggregates were free or unordered, packing densities of G3 and G4 should be still improved. Packing densities of G5 and G6 were highest due to Fuller distribution of total aggregates.

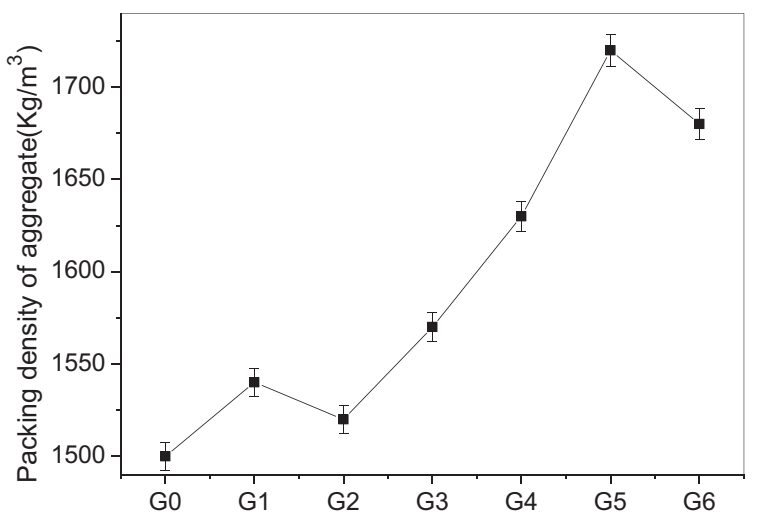

Figure 1. Packing densities of aggregates with various gradations.

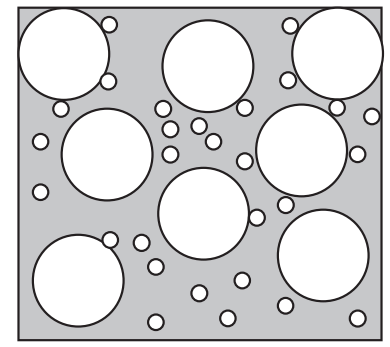

(a)

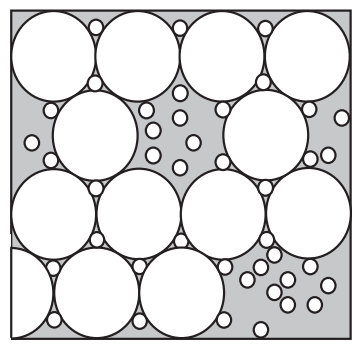

(b)

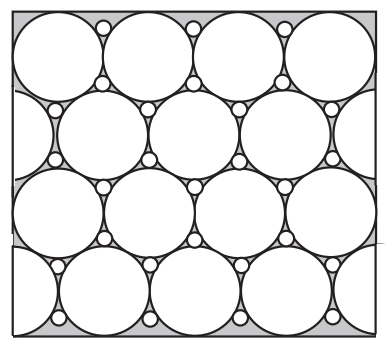

(c)

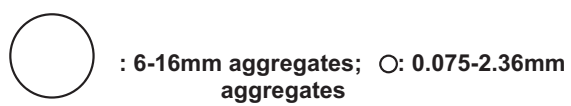

Figure 2. Aggregate density diagram of different Fuller distribution gradations: (a) fine aggregates with Fuller distribution; (b) coarse aggregates with Fuller distribution; and (c) all aggregates with Fuller distribution.

\subsection{The effect of aggregate gradation with Fuller distribution on the compressive strength of SACC}

\subsubsection{Compressive strength of SACC}

The compressive strength of SACC with different aggregate gradations at curing ages of 1,3 , and 28 days were presented in Figure 3 . There was the same trend of compressive strength of all concretes to packing density of aggregates shown in Figure 1. G0 with free aggregate gradation was used as a reference. The compressive strength of $\mathrm{G} 1$ and $\mathrm{G} 2$ at the same age was very close to the strength of $\mathrm{G} 0$. Compared with the reference $\mathrm{G} 0$, the compressive strength of concretes improved 7.7, 7.7, and $4.1 \%$ for G3 and 13.6, 19.2, and $17.8 \%$ for G5.

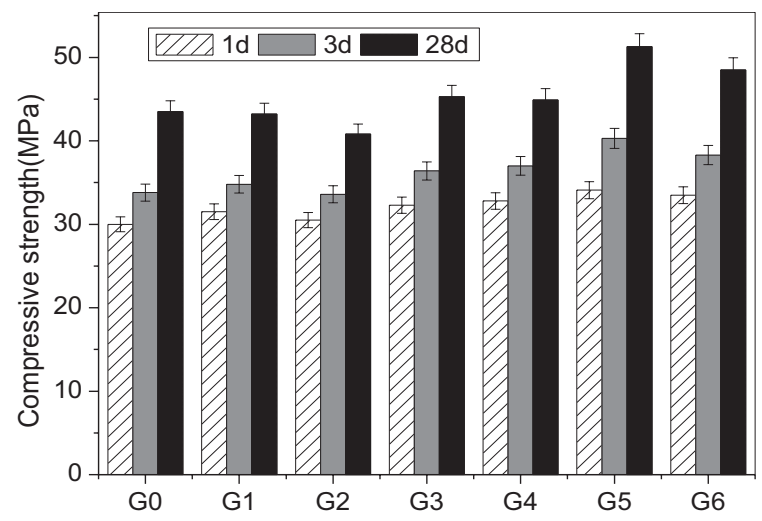

Figure 3. The compressive strength of concrete with different aggregate gradations. 


\subsubsection{The relationship between packing density of aggregates and compressive strength of SACC}

The fitting relationship between packing density of aggregates and compressive strength of SACC at curing ages of 1,3 , and 28 days was showed in Figure 4 and the fitting formula in Table 7 . The fitting relationship between packing density of aggregate and compressive strength of SACC cured for 1, 3 , and 28 days was in line with univariate linear regression equation. The correlation coefficients are evidently high: $R^{2}=0.9370, R^{2}=0.9509$, and $R^{2}=0.9071$ at curing ages of 1,3 , and 28 days, respectively. It can be seen that it is possible to adjust the aggregate gradation to improve packing density of aggregates and then affect compressive strength of concrete.

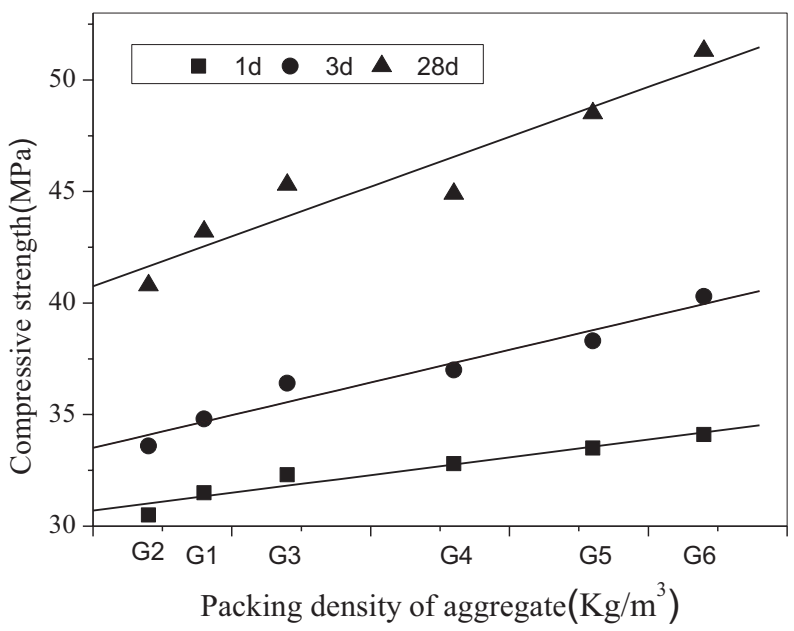

Figure 4. The fitting relationship between packing densities of aggregates and compressive strength of concrete.

Table 7. The fitting formula and correlation coefficient between packing densities of aggregates and compressive strengths of concrete.

\begin{tabular}{llc}
\hline Curing ages & Fitting formula & $\begin{array}{c}\text { Correlation } \\
\text { coefficient }\left(\boldsymbol{R}^{2}\right)\end{array}$ \\
\hline 1 day & $y=0.0159 x+6.7906$ & 0.9370 \\
3 days & $y=0.0293 x-10.46$ & 0.9509 \\
28 days & $y=0.0446 x-26.18$ & 0.9071 \\
\hline
\end{tabular}

\subsection{The effect of aggregate gradation on the water} impermeability of SACC

\subsubsection{Water impermeability of SACC}

The water impermeability refers to the concrete's ability to prevent water infiltration under a certain pressure. The ability of concrete to prevent water to its interior is better, and the impermeability is higher. The water diffusion in concrete mainly has three methods: unicom holes within the cement mortar; channels among aggregates; interface channels between cement paste and aggregates. If concrete structure is enough compact, foreign materials can be prevented from diffusion to the internal, and the water impermeability is better.

During the experiment, water seepage of G0 occurred at the pressure of $1.2 \mathrm{MPa}$, while SACC with Fuller aggregate gradation did not leak water even at the pressure of $2.1 \mathrm{MPa}$ for $168 \mathrm{~h}$. Hence, the Fuller distribution of aggregate was beneficial to density of concrete, which was consistent with the result of Figure 1.

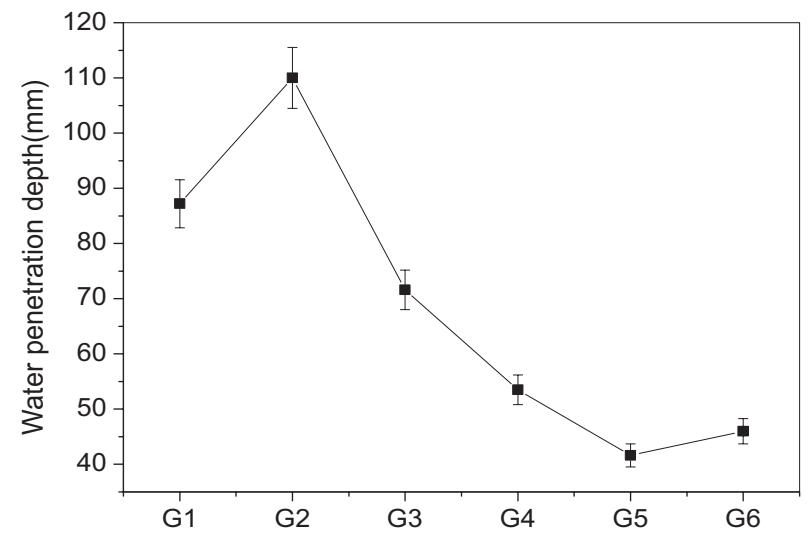

Figure 5. The influence of aggregate gradations on water penetration depth of SACC.

To find out the effect of aggregate gradation on water impermeability of SACC, the water penetration depths of SACC with various aggregate gradations at all tested ages were shown in Figure 5 . Water penetration depths of concretes with all aggregates of Fuller distribution (G5 and G6) were the least, and those with coarse aggregates of Fuller distribution ( $\mathrm{G} 1$ and $\mathrm{G} 2$ ) were the highest. There was the same trend of water penetration depth of all concretes as shown in Figures 1 and 2. It was attributed to the optimization of aggregate gradations. As aggregate gradations were optimized, packing density of aggregates increased, and then the channels between the cement and aggregates were longer, so resistance to water penetration was better.

\subsubsection{The relationship between packing density of aggregates and water penetration depth of SACC}

The relationship between packing density of aggregates and water penetration depth of SACC cured for 1, 3, and 28 days were showed in Figure 6. As was showed in Figure 6, it was a second-order polynomial relationship between packing density of aggregates and water penetration depth. The fitting formula between packing density of aggregates and water penetration depth of SACC was $y=0.002 x^{2}-6.8638 x+5862.3$ with $R^{2}=0.9799$, which indicated notable correlation. 


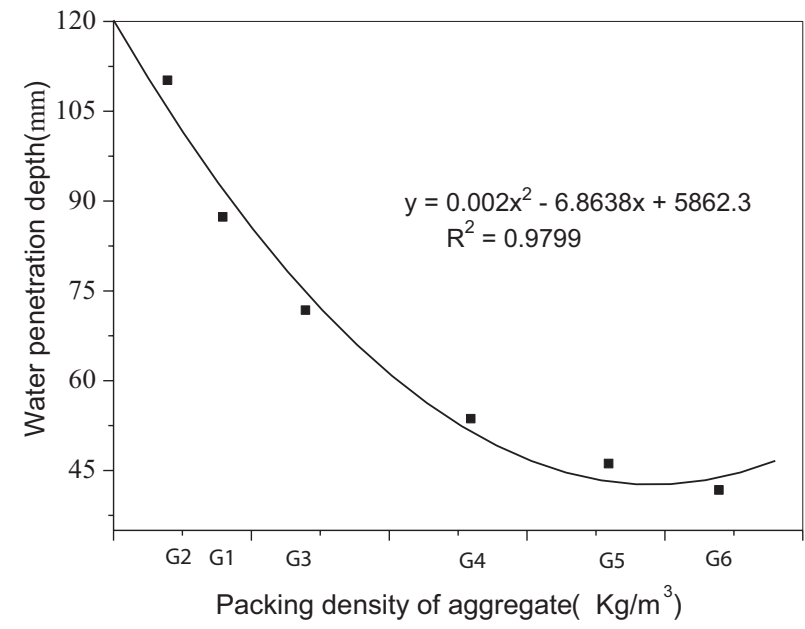

Figure 6. The fitting relationship between packing densities of aggregates and water penetration depth of SACC.

\subsection{The effect of aggregate gradation on the resistance capability to sulfate attack of SACC}

3.4.1 The resistance capability to sulfate attack of SACC The result of resistance capability to sulfate attack was showed in Figure 7. Sulfate resistance coefficients of SACC were higher than 1.0, which meant that SACC had excellent resistance capability of sulfate attack. There was an increasing trend in the sulfate resistance coefficient when aggregates with Fuller distribution gradations changed from fine aggregates or coarse aggregates to total gradations. The coefficient of G5 and $\mathrm{G} 6$ was 8 and $10 \%$ higher than that of $\mathrm{G} 0$, respectively. The coefficient of G3 and G4 was 2 and $7 \%$ higher than that of $\mathrm{G} 0$, respectively.

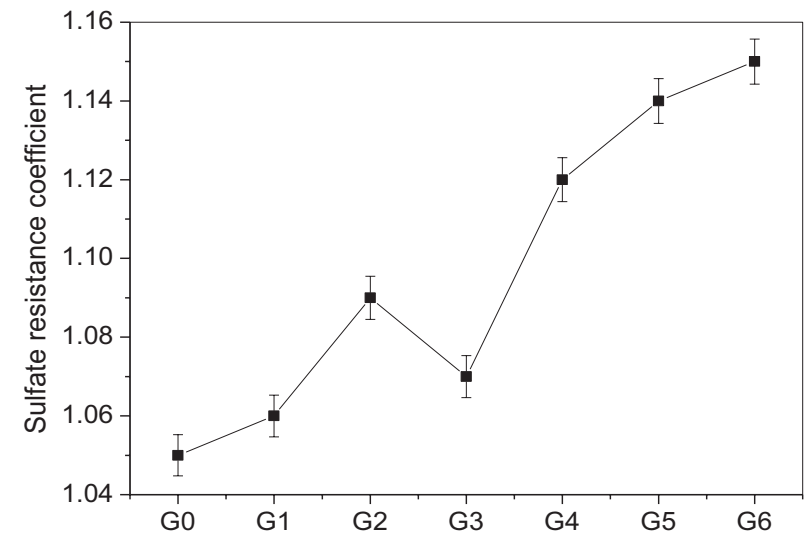

Figure 7. The influence of aggregate gradations on the resistance of SACC to sulfate attack.

\subsubsection{The relationship between packing density of aggregates and the resistance coefficient of SACC to sulfate attack}

The relationship between the packing density of aggregates and sulfate resistance coefficient was given in Figure 8. As it can be seen from Figure 8, there was a strong relationship between packing density of aggregates and sulfate resistance coefficient of SACC. The packing density of aggregate had great effect on the resistance of SACC to sulfate attack. The fitting formula between packing density of aggregates and sulfate resistance coefficient of SACC was $y=0.0 .0005 x+0.3704$ with $R^{2}=0.9585$.

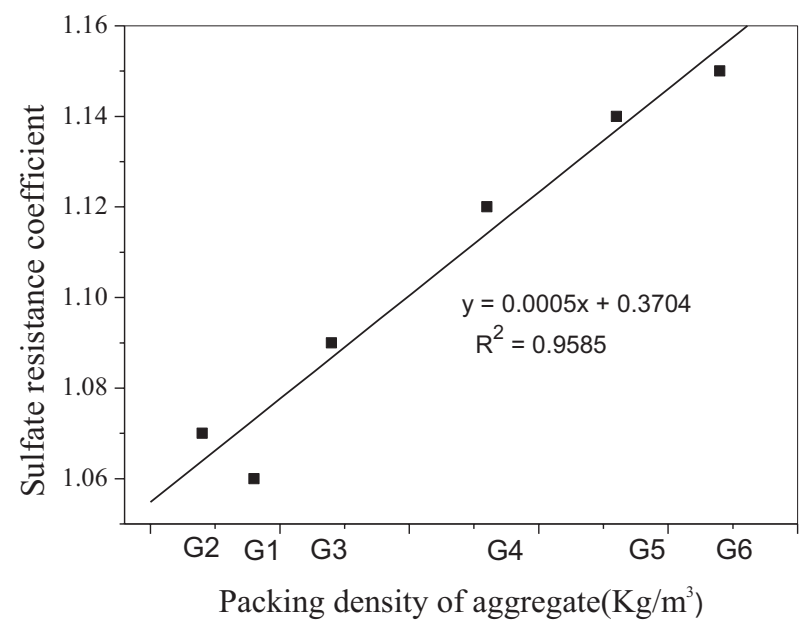

Figure 8. The fitting relationship between packing densities of aggregates and sulfate resistance of concrete.

\section{CONCLUSIONS}

In this paper, the packing densities of aggregates with various gradations were investigated; compressive strength, water impermeability, and resistance capability to sulfate attack of sulfoaluminate cement concrete with various aggregate gradations were determined. The main conclusions that can be drawn from this paper were summarized as follows:

(1) Fuller distribution of aggregates was beneficial to the close packing of aggregates, and the packing density was changed by adjusting the aggregate gradations. According to the filling effect of concrete structure, coarse aggregates built the skeleton and fine aggregates filled into the voids between coarse aggregates. The packing densities of aggregates showed a significant change trend of $\mathrm{G} 1(\mathrm{G} 2)$ with fine aggregates of Fuller distribution gradation < G3(G4) with fine aggregates of Fuller distribution gradation < G5(G6) with fine aggregates of Fuller distribution gradation.

(2) Compressive strength, water impermeability, and resistance capability to sulfate attack of SACC have the same trend of concrete with fine aggregates of Fuller distribution gradation < concrete with fine aggregates of Fuller distribution gradation < concrete with fine aggregates of Fuller distribution gradation. 
(3) There were good relationships between packing densities-compressive strength, packing densities-water penetration depth, and packing densities-sulfate resistance coefficient, and the correlation coefficients are about 0.95 . When SAC content, water-to-cement ratio, and total aggregate content were maintained, SACC properties, such as compressive strength, water impermeability, and resistance capability to sulfate attack, were determined by aggregate gradation. Hence, compressive strength, water impermeability, and resistance capability to sulfate attack of SACC can be controlled by adjusting the aggregate gradation.

\section{ACKNOWLEDGMENTS}

This work was supported by Natural Science Foundation of China (No. 51302104), Research Award Fund for outstanding young scientists of Shandong Province (SBS1202), and Foundation of University of Jinan (XBS1328). Meanwhile, this work was supported by Program for Scientific Research Innovation Team in Colleges and Universities of Shandong Province.

\section{REFERENCES}

Ashraf, W. B., \& Noor, M. A. (2011). Performanceevaluation of concrete properties for different combined aggregate gradation approaches. Procedia Engineering, 14, 2627-2634.

Bolomey, J. (1927). Determination of the compressive strength of mortars and concretes. TRACéS, 16, 22-24.

Ergul, Y., Yasin, E., \& Alaettin, K. (2004). Effect of limestone aggregate type and water-cement ratio on concrete strength. Materials Letters, 58, 772-777.

Fuller, W. B., \& Thompson, S. E. (1907). The laws of proportioning concrete. Journal of Transportation Engineering-ASCE, 59, 67-143.
Huaxin, Z., Jiaping, L., Jianzhong, L., \& Changfeng, L. (2012). Hydration kinetics process of low alkalinity sulphoaluminate cement and its thermodynamical properties. Procedia Engineering, 27, 323-331.

loannis, P. S., \& Konstantinos, G. T. (2013). Effect of composition variations on bond properties of selfcompacting concrete specimens. Construction and Building Materials, 41, 252-262.

Mucteba, U., Kemalettin, Y., \& Metin, I. (2010). The effect of the initial water to cement ratio on shielding properties of ordinary concrete. Construction and Building Materials, 52, 491-493.

Rafat, S., Paratibha, A., \& Yogesh, A. (2012). Influence of water/powder ratio on strength properties of self-compacting concrete containing coal fly ash and bottom ash. Construction and Building Materials, 29, 73-81.

Ronnen, L., \& Hashem, A. (2002). Effects of composition and exposure on the solar reflectance of Portland cement concrete. Cement and Concrete Research, 32, 1679-1698.

Sari, D., \& Pasamehmetoglu, A. G. (2005). The effects of gradation and admixture on the pumice lightweight aggregate concrete. Cement and Concrete Research, 35, 936-942.

Abdel-Jawad, Y. J., \& Abdullah, W. S. (2002). Design of maximum density aggregate grading. Construction and Building Materials, 16, 495-508.

Xin, C., Jun, C., Lingchao, L., Futian, L., \& Bing, T. (2000). Study of Ba-bearing sulphoaluminate minerals and cement. Cement and Concrete Research, 30(1), 77-81.

Xin, C., Jun, C., Lingchao, L., Futian, L., \& Bing, T. (2004). Study on the hydration of Ba-bearing calcium sulphoaluminate in the presence of gypsum. Cement and Concrete Research, 34(11), 2009-2013. 